\title{
Electrical storm after correction of an uncomplicated congenital atrial septal defect in an adult: a case report
}

\author{
Ying Liang, Feilong Hei and Yulong Guan* (1)
}

\begin{abstract}
Background: There is a paucity of published literature describing electrical storm after the correction of uncomplicated atrial septal defect (ASD) in an adult.

Case presentation: We present a 49-year-old woman with a congenital ASD combined with mild tricuspid regurgitation who denied any history of arrhythmia or other medical history. She suffered from electrical storm ( $\geq 3$ episodes of ventricular tachycardias or ventricular fibrillations) in the early stage after ASD repair with combined tricuspid valvuloplasty. During electrical storm, her electrolytes were within normal ranges and no ischemic electrocardiographic changes were detected, which suggested that retained air embolism or acute coronary thrombosis were unlikely. Additionally, echocardiographic findings and her central venous pressure $(5-8 \mathrm{mmHg}$ during the interval between attacks) failed to support the diagnosis of pericardial tamponade. After a thorough discussion, the surgeons conducted an emergent re-exploration and repeated closure of the ASD with combined DeVega's annuloplasty. Eventually, the patient recovered uneventfully, without reoccurring arrhythmias during follow-up. Although we fail to determine the definite cause, we speculate that the causes probably are iatrogenic injury of the conduction system due to a rare anatomic variation, poor intraoperative protection, latent coronary distortion during tricuspid valvuloplasty, or idiopathic or secondary abnormalities of the conduction system.
\end{abstract}

Conclusions: For most surgeons, performing re-exploration without a known etiology is a difficult decision to make. This case illustrates that re-exploration could be an option when electrical storm occurs in the early stage postoperatively. Nevertheless, surgeons should assess the benefit-risk ratio when taking this unconventional measure.

Keywords: Electrical storm, Ventricular arrhythmia, Congenital heart disease, Tricuspid valvuloplasty, Case report

\section{Background}

Atrial septal defect (ASD) is the third most common type of congenital heart disease and can present at any age [1]. This type of defect accounts for $25-30 \%$ of congenital heart defects diagnosed in adults [2]. In 2010, the European Society of Cardiology (ESC) recommended that adult patients with significant shunts (signs of right

*Correspondence: guanyulong@yahoo.com

Department of Extracorporeal Circulation, Fuwai Hospital, Chinese

Academy of Medical Sciences and Peking Union Medical College, 167

Beilishi Road, Xicheng District, Beijing 100037, People's Republic of China ventricular volume overload) and pulmonary vascular resistance $<5$ Wood units should undergo ASD closure regardless of their symptoms (class I, level B) [3]. Moreover, recent studies have observed improvements in symptoms and exercise capacities even when ASD closures are conducted in elderly patients [4-6]. Severe complications after corrective surgery for ASD include bleeding, pneumothorax, and pericardial and pleural effusions, and for older patients, stroke, heart failure, left atrial hypertension and pulmonary venous congestion are also seen incidentally $[1,4]$. Postoperative arrhythmias usually comprise transient atrial-ventricular block, atrial 
fibrillation or atrial flutter, supraventricular arrhythmia, and bradyarrhythmia $[1,4,7,8]$. It is rare to encounter electrical storm, which is defined as the occurrence of 3 or more distinct episodes of ventricular tachycardia (VT) or ventricular fibrillation (VF) within $24 \mathrm{~h}$ (also known as VT/VF storm)[9]. In this case report, we present a 49-year-old woman without an arrhythmia history who experienced VT/VF storm after ASD repair with combined tricuspid valvuloplasty. Her symptoms improved after a repeated correction. We attempt to explore the underlying causes and treatments for this VT/VF storm.

\section{Case presentation}

A 49-year-old woman complaining of exercise intolerance for 10 years was admitted to our center. Her echocardiography presented mild tricuspid regurgitation and a congenital ASD with a significant left-to-right shunt that caused structural enlargement of the right heart (echocardiographic data: LV: $41 \mathrm{~mm}$; LA: $38 \mathrm{~mm}$; RV: $24 \mathrm{~mm}$; RA: $54 \times 40 \mathrm{~mm}$; EF: $60 \%$ ). She denied any previous arrhythmia events or other past medical history. On admission, her preoperative 12-lead electrocardiogram (ECG) revealed sinus rhythm with an incomplete right bundle branch block (Fig. 1). Apart from grade 2 heart murmurs, her physical examinations were otherwise normal. Initial laboratory test results revealed normal levels of N-terminal pro-brain natriuretic peptide (NTproBNP), magnesium, and potassium. Moreover, her coagulation, biochemical, and hematological indices remained within the normal range. The patient presented as New York Heart Association (NYHA) functional class II, albeit with moderate lesions in the proximal segment of the left anterior descending artery confirmed by coronary computerized tomography (CT).

Table 1 Factors related to electrical storm in cardiac surgery

\begin{tabular}{ll}
\hline Advanced age $[12,15,18]$ & Risky \\
Higher EF $[12,19,20]$ & Protective \\
Peripheral vascular disease [12] & Risky \\
Off-pump surgery [12] & Protective \\
The need for emergent surgery [12] & Risky \\
Prolonged pump time [19] & Risky \\
Female [14, 19] & Risky \\
Pulmonary hypertension [19] & Risky \\
Systemic hypertension [19] & Risky \\
Medication-induced or congenital long QT syndrome [15, & Risky \\
20-22] & Risky \\
More complex surgery [18, 23] & Risky \\
Electrolyte disorders [18, 24] & Risky \\
Preoperative ventricular arrhythmia [20] & Risky \\
lotropes required [14] &
\end{tabular}

$E F$ ejection fraction
The patient underwent ASD repair with combined tricuspid valvuloplasty. After a median sternotomy, the surgeons placed an aortic cannula in the ascending aorta with bicaval cannulation to establish cardiopulmonary bypass (CPB). Under aortic cross-clamp conditions, cardiac arrest was achieved with antegrade cold blood cardioplegia. Then, CPB was instituted under mild hypothermia $\left(34{ }^{\circ} \mathrm{C}\right)$. After opening the right atrium, a superior sinus venosus ASD with a size of $2.0 \times 2.5 \mathrm{~cm}$ was identified. Then, the surgeons fixed the defect with running 5-0 Prolene sutures. Meanwhile, they carried out a concomitant DeVega's annuloplasty for tricuspid regurgitation. Ultimately, she was weaned from $\mathrm{CPB}$ uneventfully, with an overall duration of $\mathrm{CPB}$ of $63 \mathrm{~min}$ and a cross-clamp time of $17 \mathrm{~min}$. Of note, two transient episodes of ventricular arrhythmias (VAs) occurred at the end of surgery. However, as sinus rhythm was restored promptly, the patient was transferred to the intensive care unit (ICU) while intubated for further observation. At the first admission to the ICU, her blood pressure remained within the normal range $(102 / 63 \mathrm{mmHg})$, and the electrocardiogram revealed sinus rhythm.

However, unanticipated VTs and sequent VFs occurred one hour after admission (Fig. 2b, c). Then, the ICU staff applied external defibrillation with a 200-J biphasic shock for prompt resuscitation and added antiarrhythmic medications (including amiodarone and lidocaine) to migrate subsequent premature ventricular contractions. Soon after, the patient recovered sinus rhythm. However, after an initial uneventful recovery, the patient frequently experienced recurrent episodes of VT/VFs. The whole event is shown in Fig. 3.

The heart team suspected four possible etiologies at the first episode: electrolyte disturbances, pericardial tamponade, retained air embolism or thrombosis in coronary arteries. However, point-of-care testing revealed the standard range of potassium. Although her EF was 10\% when the first severe VT/VF storm occurred, the echocardiographic findings failed to show evidence of pericardial tamponade (no diastolic right ventricular collapse or pericardial effusion). Moreover, the central venous pressure (CVP) remained at $5-8 \mathrm{mmHg}$, despite a temporary elevation during the VT/VF storm. There were no significant ST-segment or T-wave changes during the interval between attacks and at the end of surgery (Fig. 2a). These results implied that coronary ischemia caused by coronary thrombosis or intracoronary air embolism was unlikely.

As VT/VF storm frequently transpired in the early postoperative stage and the transient arrhythmias also occurred before admission to the ICU, the cardiac experts hypothesized that the severe VA episodes 


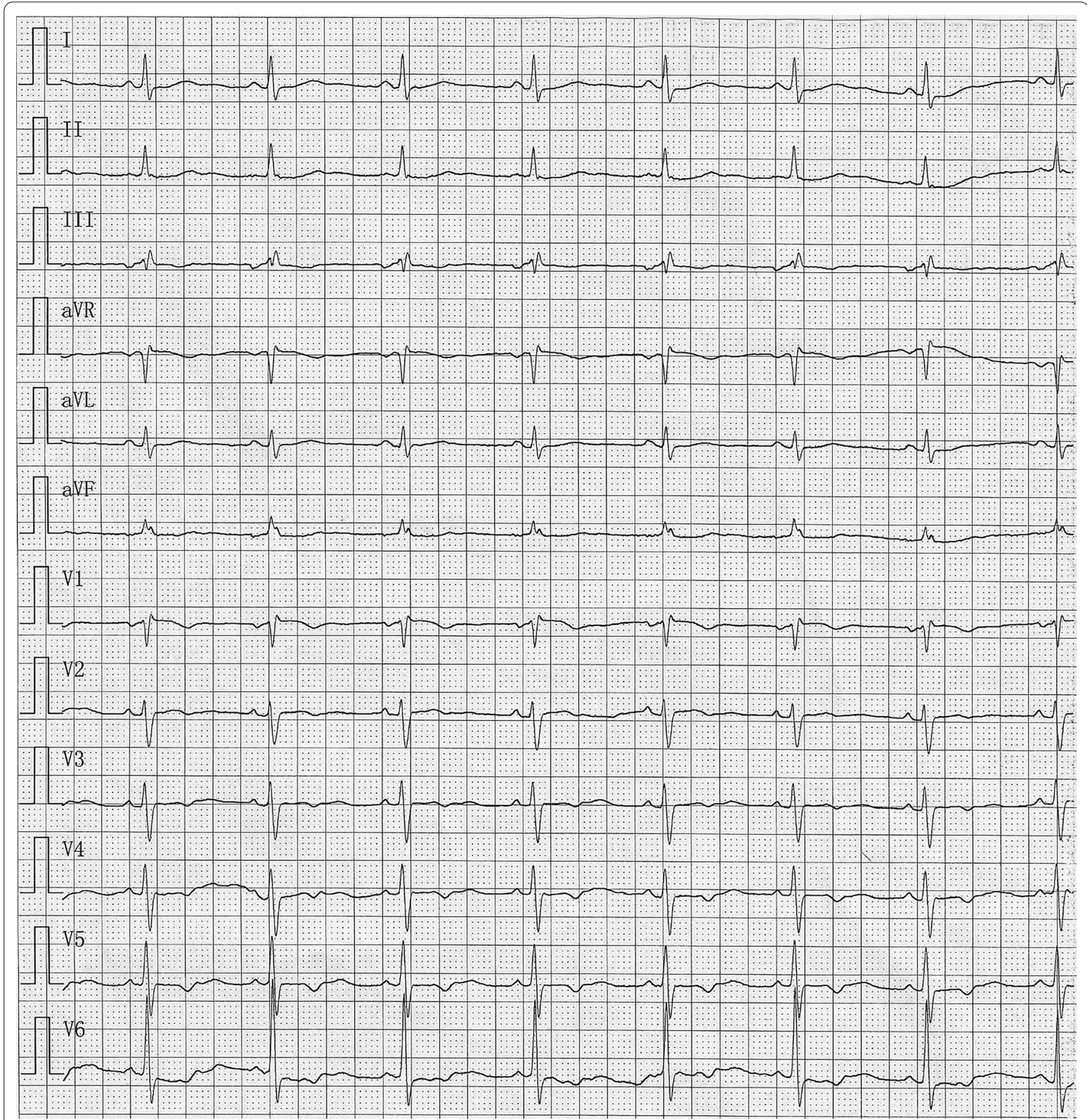

Fig. 1 Preoperative 12-lead electrocardiogram

might be associated with the surgical intervention. They attempted to explore the definite causes of this issue and focused on the two most likely explanations: trauma from the surgical sutures or underlying stenosis or occlusion of the right coronary artery caused by tricuspid valvuloplasty. Given the greater value of re-exploration in this emergent situation, we chose to forgo coronary angiography since it might not be able to detect the underlying coronary problem. After a thorough discussion, the surgeons decided to conduct an emergent re-exploration in case more life-threatening events occurred. Three hours after the first surgery, a senior surgeon initiated the reexploration. Although no significant stitching errors were detected during the second surgery, the senior surgeon carefully replaced all sutures with slight adjustments and fixed the ASD and tricuspid leaflets again to address 

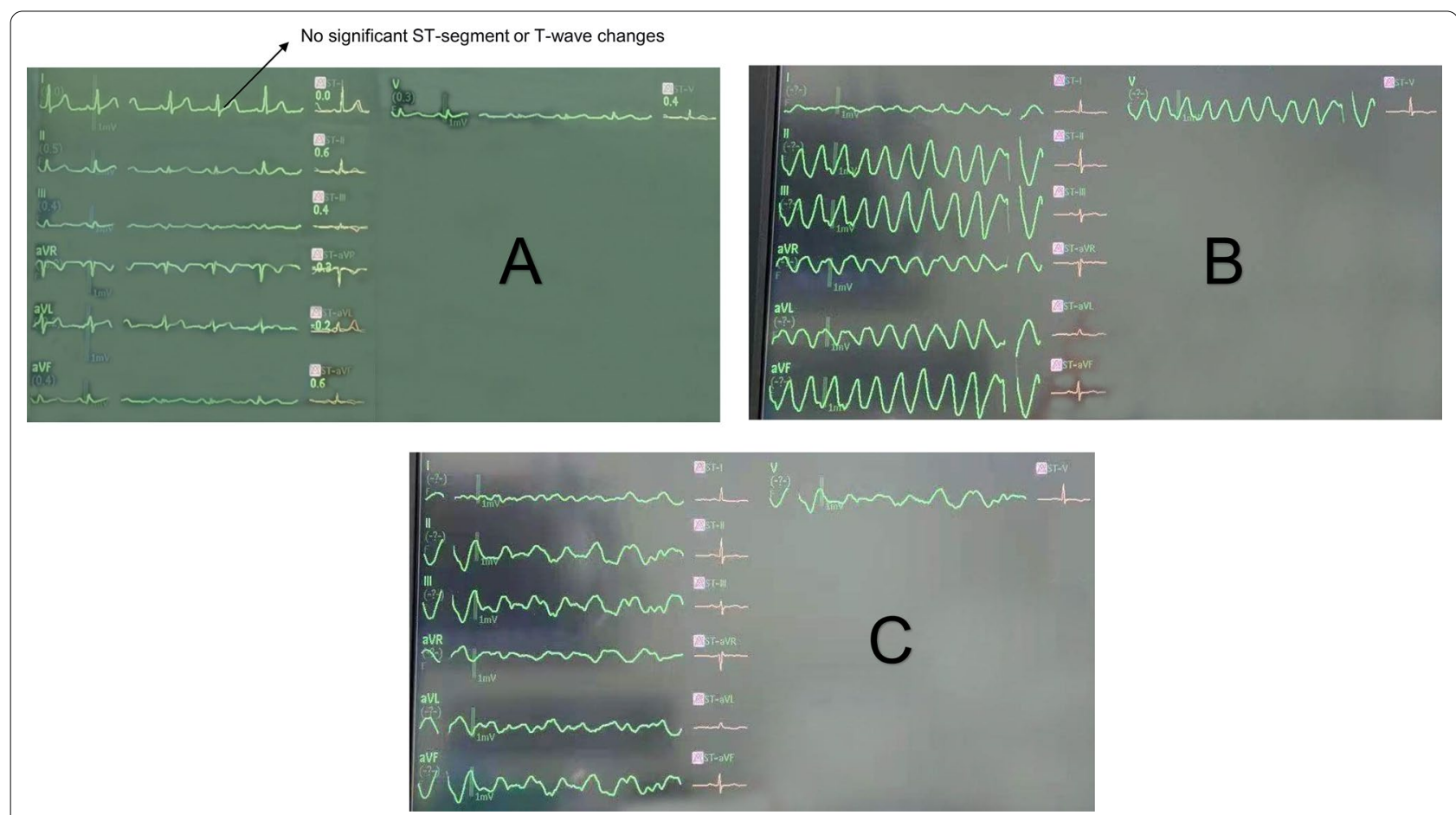

Fig. 2 Electrocardiogram of electrical storm. a normal electrocardiogram during the interval between attacks; $\mathbf{b}$ ventricular tachycardias; c ventricular fibrillations

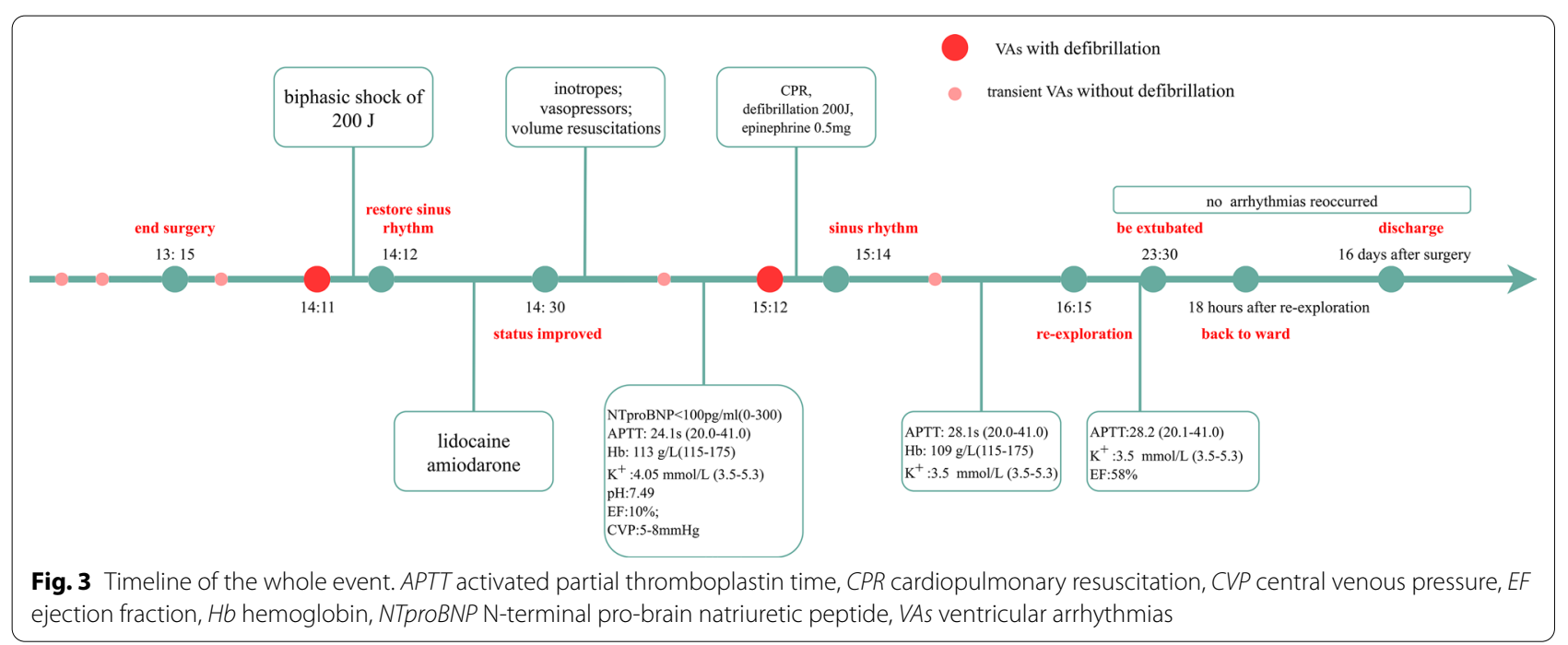

the two possible causes simultaneously. Ultimately, the patient was weaned from $\mathrm{CPB}$, with a duration of $49 \mathrm{~min}$ and a cross-clamp time of $18 \mathrm{~min}$.

After re-exploration, the patient's clinical status improved, and no arrhythmias occurred. The EF was restored immediately when her status improved. Furthermore, the results of various examinations kept within normal limits before discharge. We asked cardiac electrophysiologists to help with ECG in the whole event. They agreed that no underlying signs of inherited arrhythmias were detected in the preoperative ECG, and it's risky to conduct electrophysiological examination in that situation. As the patient displayed normal ECG over the $24 \mathrm{~h}$ after surgery, there was no indications for further electrophysiological examination postoperatively. Accordingly, we failed to obtain the 


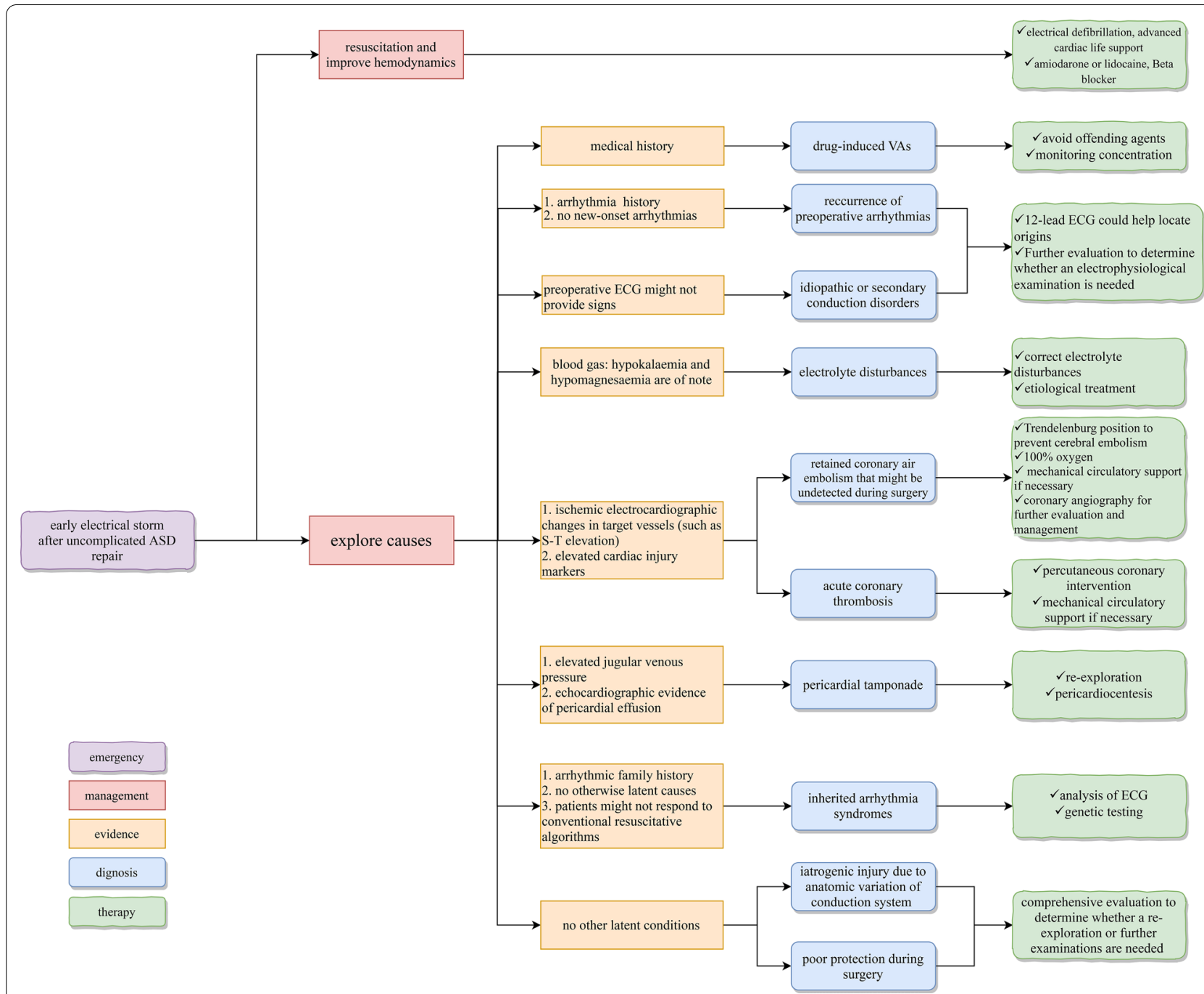

Fig. 4 Treatment strategies when electrical storm occurs after uncomplicated ASD repair. ASD atrial septal defect, ECG electrocardiogram, VAs ventricular arrhythmias

electrophysiological study. During the 6-month followup, her recovery remained uneventful, without any episodes of arrhythmias.

\section{Discussion and conclusions}

Although atrial flutters and atrial fibrillations are common in older patients with sizeable ASDs [1], VT/VF storm after the correction of ASD is rare. It is often an incidental finding after correction of tetralogy of Fallot (TOF) and left ventricular outflow tract defects $[10,11]$. To the best of our knowledge, this is the first case in the literature.

Postoperative VAs are associated with increased mortality [12-14]. The underlying risk factors for electrical storm are shown in Table 1. The precise mechanism of
VAs remains debatable. Underlying mechanisms involve the following: (1) abnormal or enhanced automaticity in ventricular myocytes and Purkinje fibers; (2) triggered activity induced by early or late afterdepolarizations; (3) reentry around a scar and functional block; and (4) reentry due to heterogeneity of ventricular repolarization [15]. Knowing the modifiable risk factors, identifying underlying causes, and providing effective management will improve patient prognosis when VAs occur. Based on our experience and previous literature, we have summarized the potential causes and treatment strategies when unexpected VT/VF storm occurs early after uncomplicated ASD repair in Fig. 4 [9, 15-17].

The heart team decide to perform repeat exploration based on two hypotheses: trauma from the surgical sutures 
or underlying stenosis or occlusion of the right coronary artery caused by tricuspid valvuloplasty, and the two problems were managed simultaneously during the second surgery. The fact that VAs haven't reoccurred after reexploration confirms our assumption to some extent. Nevertheless, in the clinical setting, neither of the two causes could be completely confirmed, as coronary stenosis and conduction system damage could not be diagnosed during surgery. Additionally, Kojima reported a patient with a nontypical ECG of prolonged QT intervals who experienced refractory VTs during ASD surgery [21]. As the patient disclosed normal preoperative and postoperative ECG, meanwhile without related family history or medical history, we failed to perform genetic testing to confirm any inherited arrhythmia syndromes. Moreover, uncommon anatomic variations and idiopathic or secondary abnormalities of the conduction system could not be ruled out completely $[25,26]$. As a whole, there is no definite evidence to date to locate the exact etiology of this VT/VF storm. Future efforts should focus on imaging methods that provide an accurate depiction of the morphology and function of the conduction system. These findings will be instructive for improving arrhythmic complications during cardiac surgery.

When VT/VF storm occurs in the early stage after uncomplicated ASD repair, the treatment strategies should focus on electrolyte disturbances, pericardial tamponade, retained air embolism or acute coronary thrombosis. Additionally, idiopathic or secondary abnormalities of the conduction system, inherited arrhythmia syndromes, iatrogenic injury of the conduction system due to anatomic variations or poor intraoperative protection should also be considered.

For most surgeons, performing re-exploration without a known etiology is a difficult decision to make. This case illustrates that re-exploration could be an option when emergent VT/VF storm occurs in the early postoperative stage. Nevertheless, surgeons should assess the benefit-risk ratio when taking this unconventional measure.

\section{Abbreviations}

EF: Ejection fraction; LA: Left atrium; LV: Left ventricle; RA: Right atrium; RV: Right ventricle.

\section{Acknowledgements}

Not applicable.

\section{Authors' contributions}

Author YL undertook the main work of data collection, follow-up, analysis, and writing; Author FH wrote and interpreted the manuscript. Author YG, revised and interpreted the manuscript, and will do the subsequent contact. All authors read and approved the final manuscript.

\section{Funding}

This article is supported by National Natural Science Foundation of China (81670077), Innovative Research Foundation of Peking Union Medical College
(2019-1002-77), CAMS Innovation Fund for Medical Sciences (2020-12M-C\&T$\mathrm{B}$-066). The funding body played the role of in the design of the study and collection, analysis, and interpretation of data and in writing the manuscript.

Availability of data and materials

Data sharing not applicable to this article as no datasets were generated or analyzed during the current study.

\section{Declarations}

\section{Ethics approval and consent to participate}

This study was performed in accordance with the principles of the Declaration of Helsinki, and the patient provided informed consent. As the study is a case report, there is no ethics committee to approve the study.

\section{Consent for publication}

Written informed consent was gained from the patient for the publication of this article.

\section{Competing interests}

The authors declare that they have no competing interests.

Received: 8 March 2021 Accepted: 15 July 2021

Published online: 22 July 2021

\section{References}

1. Webb G, Gatzoulis MA. Atrial septal defects in the adult: recent progress and overview. Circulation. 2006;114(15):1645-53.

2. Lindsey JB, Hillis LD. Clinical update: atrial septal defect in adults. Lancet. 2007;369(9569):1244-6.

3. Baumgartner H, Bonhoeffer P, De Groot NM, de Haan F, Deanfield JE, Galie $\mathrm{N}$, et al. ESC guidelines for the management of grown-up congenital heart disease (new version 2010). Eur Heart J. 2010;31(23):2915-57.

4. Geva T, Martins JD, Wald RM. Atrial septal defects. Lancet. 2014;383(9932):1921-32.

5. Konstantinides S, Geibel A, Olschewski M, Görnandt L, Roskamm H, Spillner $\mathrm{G}$, et al. A comparison of surgical and medical therapy for atrial septal defect in adults. N Engl J Med. 1995;333(8):469-73.

6. Brida M, Diller GP, Kempny A, Drakopoulou M, Shore D, Gatzoulis MA, et al. Atrial septal defect closure in adulthood is associated with normal survival in the mid to longer term. Heart. 2019;105(13):1014-9.

7. Bové T, François K, De Groote K, Suys B, DeWolf D, Van Nooten G. Closure of atrial septal defects: Is there still a place for surgery? Acta Chir Belg. 2005;105(5):497-503.

8. Butera G, Carminati M, Chessa M, Youssef R, Drago M, Giamberti A, et al. Percutaneous versus surgical closure of secundum atrial septal defect: comparison of early results and complications. Am Heart J. 2006;151(1):228-34.

9. Deyell MW, AbdelWahab A, Angaran P, Essebag V, Glover B, Gula LJ, et al. 2020 Canadian Cardiovascular Society/Canadian Heart Rhythm Society Position Statement on the management of ventricular tachycardia and fibrillation in patients with structural heart disease. Can J Cardiol. 2020:36(6):822-36.

10. Nielsen JC, Lin YJ, de Oliveira Figueiredo MJ, Sepehri Shamloo A, Alfie A, Boveda S, et al. European Heart Rhythm Association (EHRA)/Heart Rhythm Society (HRS)/Asia Pacific Heart Rhythm Society (APHRS)/Latin American Heart Rhythm Society (LAHRS) expert consensus on risk assessment in cardiac arrhythmias: use the right tool for the right outcome, in the right population. Europace. 2020;22(8):1147-8.

11. Maury P, Sacher F, Rollin A, Mondoly P, Duparc A, Zeppenfeld K, et al. Ventricular arrhythmias and sudden death in tetralogy of Fallot. Arch Cardiovasc Dis. 2017;110(5):354-62.

12. El-Chami MF, Sawaya FJ, Kilgo P, Stein W, Halkos M, Thourani V, et al. Ventricular arrhythmia after cardiac surgery: incidence, predictors, and outcomes. J Am Coll Cardiol. 2012;60(25):2664-71.

13. Fuchs SR, Smith AH, Van Driest SL, Crum KF, Edwards TL, Kannankeril PJ. Incidence and effect of early postoperative ventricular arrhythmias after congenital heart surgery. Heart Rhythm. 2019;16(5):710-6. 
14. Ascione R, Reeves BC, Santo K, Khan N, Angelini GD. Predictors of new malignant ventricular arrhythmias after coronary surgery: a case-control study. J Am Coll Cardiol. 2004;43(9):1630-8.

15. Al-Khatib SM, Stevenson WG, Ackerman MJ, Bryant WJ, Callans DJ, Curtis $A B$, et al. 2017 AHA/ACC/HRS guideline for management of patients with ventricular arrhythmias and the prevention of sudden cardiac death: a report of the American College of Cardiology/American Heart Association Task Force on Clinical Practice Guidelines and the Heart Rhythm Society. J Am Coll Cardiol. 2018;72(14):e91-220.

16. Fogel Rl, Prystowsky EN. Management of malignant ventricular arrhythmias and cardiac arrest. Crit Care Med. 2000;28(10 Suppl):N165-9.

17. Kowlgi GN, Cha YM. Management of ventricular electrical storm: a contemporary appraisal. Europace. 2020;22(12):1768-80.

18. Peretto G, Durante A, Limite LR, Cianflone D. Postoperative arrhythmias after cardiac surgery: incidence, risk factors, and therapeutic management. Cardiol Res Pract. 2014;2014:615987.

19. Yeung-Lai-Wah JA, Qi A, McNeill E, Abel JG, Tung S, Humphries KH, et al. New-onset sustained ventricular tachycardia and fibrillation early after cardiac operations. Ann Thorac Surg. 2004;77(6):2083-8.

20. Tam SK, Miller JM, Edmunds LH Jr. Unexpected, sustained ventricular tachyarrhythmia after cardiac operations. J Thorac Cardiovasc Surg. 1991;102(6):883-9.

21. Kojima A, Shikata F, Okamura T, Higaki T, Ohno S, Horie M, et al. Refractory ventricular fibrillations after surgical repair of atrial septal defects in a patient with CACNA1C gene mutation — case report. J Cardiothorac Surg. 2017;12(1):118

22. Tisdale JE, Chung MK, Campbell KB, Hammadah M, Joglar JA, Leclerc J, et al. Drug-induced arrhythmias: a scientific statement from the American Heart Association. Circulation. 2020;142(15):e214-33.

23. Janousek J, Paul T, Bartáková H. Role of late potentials in identifying patients at risk for ventricular tachycardia after surgical correction of congenital heart disease. Am J Cardiol. 1995;75(2):146-50.

24. Laslett DB, Cooper JM, Greenberg RM, Yesenosky GA, Basil A, Gangireddy $C$, et al. Electrolyte abnormalities in patients presenting with ventricular arrhythmia (from the LYTE-VT Study). Am J Cardiol. 2020;129:36-41.

25. Moore JP, Aboulhosn JA. Introduction to the congenital heart defects: anatomy of the conduction system. Card Electrophysiol Clin. 2017;9(2):167-75

26. Bharati S, Lev M. Congenital abnormalities of the conduction system in sudden death in young adults. J Am Coll Cardiol. 1986;8(5):1096-104.

\section{Publisher's Note}

Springer Nature remains neutral with regard to jurisdictional claims in published maps and institutional affiliations.
Ready to submit your research? Choose BMC and benefit from:

- fast, convenient online submission

- thorough peer review by experienced researchers in your field

- rapid publication on acceptance

- support for research data, including large and complex data types

- gold Open Access which fosters wider collaboration and increased citations

- maximum visibility for your research: over $100 \mathrm{M}$ website views per year

At BMC, research is always in progress.

Learn more biomedcentral.com/submissions 